\title{
A LIDERANÇA E A GESTÃO ESTRATÉGICA DE PESSOAS NAS INSTITUIÇÕES FINANCEIRAS
}

\author{
Nadiessa Cappellari ${ }^{1}$, Silvio Roberto Stefano ${ }^{1}$, Léo Raifur ${ }^{1}$, Dayanne Marciane Gonçalves ${ }^{1}$ \\ ${ }^{1}$ Instituição afiliada: Universidade Estadual do Centro-Oeste UNICENTRO - PPGADM \\ E-mail(s): professor-silvio@hotmail.com
}

\begin{abstract}
Resumo
Esta pesquisa tem como propósito analisar os estilos de liderança, a orientação para resultados, e as praticas de gestão estratégica de pessoas utilizadas pelas instituições financeiras públicas e privadas. $\mathrm{O}$ estudo possui corte temporal transversal e é de natureza exploratória. A pesquisa foi baseada em questionários estruturados que procuram medir as Políticas de Recursos Humanos (14 questões) e as Características de Liderança (13 questões). Os dados foram coletados no mês de março de 2015 em 13 agencias bancárias com uma amostra de 124 bancários escolhidos aleatoriamente. Com uso da Análise Fatorial, as 27 questões iniciais foram resumidas em três fatores (dimensões): 1) Políticas de Recursos Humanos; 2) Liderança: Motivação e Eficiência em Resultados, e; 3) Liderança: Foco em Resultados. Os resultados evidenciam a tendência dos gestores em adotar a liderança transformada, fator que favorece o comprometimento dos funcionários com a missão e objetivos da organização. Já o estilo de liderança predominente é o orientado para resultados, demonstrando adequação aos objetivos empresariais. Por fim verificou-se o foco das instituições financeiras no comprometimento, retratando a satisfação dos colaboradores com as políticas de gestão de pessoas empregadas. Espera-se que essa pesquisa possa favorecer a identificação das lideranças e a gestão estratégica de pessoas tanto nas instituições financeiras, como como nas demais organizações, uma vez que demonstra que quanto maior for o investimento em políticas de gestão estratégica de pessoas com visão transformada, e orientada para resultados, maior a satisfação dos colaboradores.
\end{abstract}

Palavras-chaves: Gestão Estratégica de Pessoas. Políticas de Recursos Humanos. Liderança.

\begin{abstract}
This research aims to examine the leadership styles, the results orientation and strategic management practices of people used by financial institutions public and private. The study has cross-cutting and time is exploratory in nature. The research was based on structured questionnaires that seek to measure the Human Resources Policies (14 issues) and Leadership Characteristics (13 questions). Data were collected in March in 13 bank branches with a sample of 124 randomly chosen bank. With use of factor analysis, the 27 initial questions were summarized in three factors (dimensions): 1) Human Resources Policies; 2) Leadership: Motivation and Efficiency in results, and; 3) Leadership: Focus on Results. The results show the tendency of managers to adopt the transformed leadership, a factor that favors the employee commitment to the mission and goals of the organization. But the leadership style is resultsoriented, showing suitability for business goals. Finally there was the focus of financial institutions in the compromise, portraying the satisfaction of employees with the employed people management policies. It is hoped that this research will facilitate the identification of leadership and strategic management of people both in the financial institutions, such as other organizations, since it shows that the higher investment in strategic management policies of people transform vision, and result-oriented, higher employee satisfaction.
\end{abstract}

Keywords: Strategic People Management. Human Resources Policies. Leadership.

\section{Introdução}

R. Eletr. do Alto Vale do Itajaí - REAVI, v. 4, n. 6, p. I- F,mai., 2016.

ISSN 2316-4190, DOI: 10.5965/23164190104062015014 
O sistema financeiro brasileiro busca contribuir para o desenvolvimento econômico, social e sustentável do país. Em um cenário globalizado, enfrenta os mesmos desafios que as demais organizações: alta competitividade, constantes inovações tecnológicas e excelência de produtos e na prestação de serviços. Para isso conta com a efetividade do quadro de pessoal, com profissionais cada vez mais qualificados e responsáveis pelo resultado final das instituições financeiras (FEBRABAN, 2013).

Em uma empresa de alto desempenho, os negócios e as pessoas são conduzidos de maneira que "coração e mente" trabalhem juntos (DIJK; EIGENHUIS, 2008). Em meio a rápidas transformações e mudanças nos padrões de exigência, a gestão de pessoas deve amparar as organizações, pois é ela a responsável pela maneira que as empresas se estruturam para gerenciar e orientar o comportamento humano no trabalho (FISHER, 2002).

Como consequência das mudanças no meio ambiente das organizações, a capacitação dos gestores passou a incluir temas voltados para a área de desenvolvimento de pessoal e avaliação de seu desempenho e comportamento, tanto que as tendências da área se mostram cada vez mais humanizadas e participativas, substituindo os modelos tradicionais e obsoletos. O investimento e gerenciamento do capital humano passaram a ser indispensáveis para que uma instituição seja altamente competitiva e um grande desafio de gestão para os líderes. Assim, a gestão de pessoas passou a ter um novo sentido nas organizações e a se integrar no planejamento estratégico da mesma (ANDRADE, LOPES E STEFANO, 2013).

Assumindo esse novo papel, a gestão estratégica de pessoas vem com a missão de alinhar as pessoas a estratégia da organização; gerir pessoas para atuarem em níveis mais elevados de desempenho, bem como permitir para os indivíduos alcançar tanto objetivos organizacionais quanto pessoais (MASCARENHAS, 2008).

A visão estratégica de pessoas também evoluiu para se adequar ao contexto atual, transformando o modelo de controle em comprometimento. No modelo de controle o ser humano é considerado fator de produção, recurso e apenas mais um número. A tendência é de que as empresas seguidoras do modelo anterior migrem para a estratégia de comprometimento, pois esta visualiza o ser humano como pessoa, como parceiro efetivo na busca dos objetivos organizacionais e de agregação de valor a sociedade (ALBUQUERQUE, 2002).

Acompanhar essa e tantas outras mudanças, bem como se destacar em um cenário altamente competitivo e exigente fica em grande parte sob responsabilidade do líder, agora também visto como agente estratégico. Como afirma Drucker (1996), líder é a pessoa que possui seguidores e usa sua influencia sobre os outros visando atingir metas e resultados organizacionais. A liderança eficaz exige atributos aliados a resultados, ou seja, deve haver a consecução de algo (ULRICH, 2000).

Dentre as diversas abordagens sobre o tema aqui exposto, as lideranças transformacionais e transacionais estão entre as que mais se destacam na literatura. A transacional se caracteriza pelo gerenciamento passivo, deixando claro aos seguidores o que e como fazer para atingir metas e objetivos. Estabelece com a equipe uma relação de simples troca, sem vínculo e comprometimento. Pela panorâmica atual, deve haver uma melhor aceitação da liderança transformacional, pois ela inspira a mudança de atitudes e comportamentos dos funcionários; cria comprometimento com a missão e objetivos da organização; além de motivar os seguidores a fazer esforços extraordinários pela organização (LIMONGI-FRANÇA; ARELLANO, 2002).

Observa-se que não há uma regra definida, uma vez que existe uma variedade de estilos e estes podem ser válidos e eficazes de acordo com a situação. A abordagem atual sugere ao líder uma posição mais dinâmica e flexível, em uma postura situacional onde a atuação se encaixa ao contexto que engloba a organização.

Diante dos conceitos e justificativa da importância do tema exposto, o estudo busca responder qual o grau de importância da liderança orientada para resultados para os bancários da cidade? Quais estilos de liderança são aplicados nas Instituições Financeiras? Qual o grau de 
concordância com as políticas de recursos humanos (controle ou comprometimento)? Neste sentido apresenta como objetivo geral analisar os estilos de liderança, a orientação para resultados, e as praticas de gestão estratégica de pessoas utilizadas pelas instituições financeiras (públicas e privadas).

Com este estudo espera-se contribuir diante das instituições financeiras, identificando os estilos de liderança adotados e os impactos sobre seus liderados, bem como verificar a orientação das mesmas para os resultados direcionando seus esforços em prol dos objetivos e metas organizacionais. Além de analisar se as práticas de gestão estratégica de pessoas estão de acordo com as necessidades das instituições.

A estrutura deste artigo é composta por referencial teórico, abordando os temas liderança orientada para resultados e, também, estratégia e gestão de pessoas; a metodologia de pesquisa, trazendo a abordagem, as técnicas e o delineamento da pesquisa; os resultados e discussões e as considerações finais.

\section{Referencial Teórico}

\subsection{Liderança Orientada para Resultados}

O sucesso das organizações é responsabilidade do líder que conduz a empresa. Pois como afirma Drucker (1999), líder é a pessoa que possui seguidores e usa sua influencia sobre os outros visando atingir metas e resultados organizacionais. Vindo ao seu encontro, Maximiano (2009) acrescenta que a liderança é o processo de conduzir ações ou influenciar o comportamento de outras pessoas para o atingimento das metas organizacionais.

Para Foley e Smith (2010), a liderança eficaz pode ser um diferencial competitivo a fim de atingir as metas organizacionais. Para fazer isso, os líderes devem ser capazes de fornecer inspiração, motivação e direção clara para sua equipe. Para qualquer tipo ou tamanho do negócio, liderança eficaz proporciona muitos benefícios, ajudando a organização a alcançar o sucesso e estabilidade. Na ausência de uma liderança eficaz, as organizações geralmente crescem lentamente e podem perder a sua direção e competitividade. Dessa forma é imprescindível que a liderança seja orientada para resultados, devendo haver metas para a consecução de objetivos maiores (ULRICH, 2000).

Destaca-se a questão de que liderança é diferente do gerenciamento. O gerenciamento está relacionado a lidar com a complexidade e estrutura organizacional, mecanismos de controle, eficiência, técnicas empresarial, mensuração de resultados, entre outras características. Enquanto a liderança é mais abrangente, está relacionada a lidar com desafios, com ênfase nas pessoas, na autonomia, no comprometimento dos colaboradores, nos propósitos e princípios, na eficácia, etc (STEFANO, 2008).

Os três estilos básicos de liderança formal causam impacto no clima social das organizações. São eles: autocrático, liberal e democrático. Para Maximiano (2009) o estilo de comportamento do líder refere-se ao que ele faz e como o faz.

Assim, verifica-se que o estilo autocrático envolve o uso da autoridade formal e de seus instrumentos, eliminando a participação ou influência dos subordinados no processo decisório. Já o estilo democrático diz respeito à influência ou participação dos subordinados no processo de decisão. E no estilo liberal, o gerente transfere sua autoridade para os subordinados, conferindolhes o poder de tomar decisões (STEFANO, 2008).

O tema liderança é pauta de estudo para vários pesquisadores, dessa forma apresenta diversas evoluções em suas teorias. No século XX, a teoria dos traços defendia a ideia de que o indivíduo teria de possuir qualidades genéticas para ser um líder. Atributos de personalidade, sociais, físicos e intelectuais diferenciam os líderes em relação aos "não líderes". Dessa forma, certas características não poderiam ser adquiridas através da aprendizagem ou treinamento, sendo intransferíveis de uma pessoa para outra (BOWDITCH; BUONO, 2002). Dependendo do estilo 
de liderança adotado, há uma diferenciação no impacto sobre o comportamento e motivação dos trabalhadores. Os resultados também são distintos, com níveis de desempenho alterados.

Já na década de 50 surgiu a abordagem comportamental, defendendo que a maioria das pessoas podem vir a se tornar líderes, pois o aprendizado e a experiência permitem a obtenção de habilidades e competências necessárias para seu exercício. A liderança é almejada principalmente para pessoas com função de gerência, embora outras pessoas da organização também possam exercê-la (ROBBINS, 2011).

Ainda segundo Robbins (2011), em 1960 surgiu outra variável na definição do processo de liderança, a abordagem situacional. Ela defende que o tipo da liderança dependerá do contexto ou situação que engloba a organização, aconselhando uma liderança mais dinâmica e flexível, em vez de estática. Nela, o estilo eficaz deve se ajustar à situação, adequado à circunstância correspondente, avaliando o contexto exposto. Para isso o líder deve ter clareza das tarefas e trabalhos a serem realizados; um bom relacionamento com as pessoas; e saber avaliar o grau de maturidade de sua equipe, para aproveitar as capacidades e disponibilidades de cada colaborador.

Contudo, pode-se afirmar que o estilo de liderança praticado influencia diretamente no clima, comportamento e motivação das pessoas, pois a equipe pode ser considerada como um reflexo de sua liderança. O líder é o que torna um grupo de pessoas na organização em uma equipe em prol de objetivos em comum. A forma com que realiza a condução de sua equipe reflete diretamente nos resultados coletivos e individuais (ANDRADE; LOPES; STEFANO, 2013).

Embora as pessoas possuam personalidade própria e apresentem diferenças em relação aos seus conhecimentos, habilidades e comportamentos, existem características em comum que permitem identificar o estilo de liderança praticado. Na literatura podem ser encontrados diversos estilos, situações e definições de personalidade de um líder. Neste trabalho serão abordados os estilos de liderança transformacionais e transacionais.

A liderança transacional (ou tradicional) tem como características marcantes o gerenciamento passivo, pois aguarda os fatos e só toma providências quando o erro já ocorreu. Na busca por atingir metas e objetivos, deixa claro aos seguidores o que deve ser feito e como fazer. Ele estabelece com a equipe uma relação de simples troca, não gerando vínculo e comprometimento, baseado apenas na autoridade burocrática. Este tipo de liderança pode ser efetiva, pois favorece a manutenção do status quo, embora não resulte em mudança organizacional (LIMONGIFRANÇA; ARELLANO, 2002).

Já a liderança transformacional, segundo Limongi-França e Arellano (2002), pode ser vista como um processo de influenciar a mudança de atitudes e comportamentos dos funcionários, além de criar um comprometimento com a missão e objetivos da organização. Inspiram os seguidores a ir além das expectativas, os posicionando em níveis mais elevados, abdicando de interesses próprios a favor da organização. Estes líderes provocam e transformam as crenças, atitudes e motivações de seus seguidores, inspirando-os a fazerem esforços extraordinários.

Pesquisas como de Aroma e da Silva (2003) assinalam que os líderes transformacionais em instituições financeiras são mais efetivos e carismáticos, causando maior comprometimento, satisfação, lealdade, envolvimento e desempenho dos liderados, enquanto que os transacionais tentem a manter o status-quo com menor influencia sobre a aprendizagem da equipe, de acordo com a amostra analisada naquele estudo.

Montana e Charnov (2003) constataram, com base nos estudos já testados e apresentados desde os tempos bíblicos, que não existe um estilo de liderança ideal, pois os líderes como qualquer ser humano estão sujeitos a fraquezas e instabilidades sendo assim passíveis de erros. Dessa forma seu desenvolvimento requer um contínuo esforço de autoconhecimento, de conhecimento das outras pessoas, do ambiente interno e da sociedade em seu entorno. O líder deverá servir de exemplo para os membros da organização, promovendo a confiança, identificação e influência sobre as pessoas. Pessoas entusiasmadas pelo aprendizado irão exercer 
influência duradoura sobre as demais, buscando a mudança, ao invés de tentarem resistir a ela. Para isso o líder deve ser dotado de visão, coragem e humildade para aprender continuamente.

\subsection{Estratégia e Gestão de Pessoas}

É cada vez maior o número de empresas que adota o planejamento estratégico em sua gestão, medida essa que faz com que as organizações tenham uma visão melhor do futuro, podendo realizar inúmeros planos de ação adequados às diversas fases que enfrentam no atualizado e competitivo mundo de hoje. A estratégia baseia-se na composição de ações que os gerentes/administradores utilizam para atrair clientes, fidelizar colaboradores e alcançar o desempenho organizacional ao nível de competitividade (FRAGOSO, 2009).

A necessidade de evoluir de maneira eficaz fez com que vários aspectos relacionados à gestão estratégica de pessoas fossem sendo substituídas e modificadas ao longo do tempo. Ocorre uma mudança importante no foco estratégico com a transição de uma estratégia de controle (econômica e/ou tradicional) para uma estratégia o de comprometimento (transformada) (ANDRADE; LOPES; STEFANO, 2013).

Na estratégia de controle os empregados são vistos como números, custos e fator de produção, que, para desempenhar bem as funções, devem ser mandados e controlados; estrutura altamente hierarquizada, com produção em massa, trabalho especializado, com baixo nível de exigência em qualificação e baixa participação dos empregados na tomada de decisões (ALBUQUERQUE, 2002).

Já a estratégia de comprometimento é caracterizada pela valorização dos talentos humanos; a atração e manutenção de pessoas com potencial e qualificação; criação de condições favoráveis à motivação individual; mobilização dos grupos em torno das metas organizacionais; possibilidade de desenvolvimento profissional na própria empresa; políticas de recursos humanos integradas à realidade da empresa e ao seu contexto de atuação; produção flexível gerando trabalhos enriquecidos e desafiadores, confiança mútua e alta participação dos empregados nas tomadas de decisões (ALBUQUERQUE, 2002).

Armstrong (2008) destaca que a mudança de estratégia de recursos humanos requer dos profissionais da área capacidade de visualizar situações futuras, de longo prazo, projetando ações solucionadoras de problemas. Para isso devem pensar cuidadosamente sobre o que eles estão fazendo no contexto de sua organização, oferecendo assessoria, orientação e serviços que ajudarão a organização a alcançar seus objetivos estratégicos.

Neste sentido, a gestão de pessoas pode contribuir com o desenvolvimento da estratégia organizacional na medida em que passa a atrair, manter e desenvolver pessoas comprometidas com os atingimento dos resultados organizacionais. Logo, busca proporcionar maior satisfação aos seus funcionários, uma vez que a motivação dos mesmos pode favorecer a entrega de resultados mais eficazes e produtivos, podendo alavancar os negocias positivamente (DUTRA, 2013).

\section{$3 \quad$ Metodologia}

Trata-se de um estudo transversal com abordagem quantitativa, pois segundo Creswell (2007) ela pode proporcionar descrições numéricas de tendências, atitudes ou opiniões de uma amostra. Quanto aos fins é caracterizada como exploratória, pois segundo Cooper e Schindler (2003) enfatiza a descoberta de ideias e discernimentos. Também é descritiva, pois procurou descrever o comportamento dos fenômenos que são as percepções e entendimento dos funcionários das instituições financeiras analisadas.

Na pesquisa, foram utilizados questionários estruturados não disfarçados e autopreenchidos. Os bancarios avaliaram em uma escala likert de 5 pontos (de 1 - Sem importância até 6 - Total Importância), 14 questões sobre sobre as características dos líderes sendo as mesmas divididas 
em questões sobre motivação e eficiência na obtenção de resultados e relativas a orientação para resultados adaptado Ulrich (2000) e Stefano (2008), além de 13 questões sobre o grau de importância das políticas de recursos humanos da instituição em que trabalha, sendo estas baseadas no modelo de Albuquerque (2002) e Stefano (2008). Também foi investigado o perfil social da amostra com 5 (cinco) questões sobre sexo, faixa etária, cargo atual, tempo de serviço na agencia e banco e escolaridade.

Tendo em vista o número elevado de variáveis, foi utilizada a análise fatorial. A análise fatorial (AF) é uma técnica multivariada que tem por objetivo reduzir um número grande de variáveis em um conjunto reduzido de fatores (dimensões) assegurando que uma parte significativa da variância seja explicada. Esse método também possibilita a eliminação da multicolinearidade entre as variáveis explicativas, incluindo as intercorrelações e aproveitando a contribuição do conjunto máximo de indicadores para o modelo. De outra forma, parte das variáveis explicativas multicolineares precisariam ser excluídas da análise (RAIFUR, 2013).

$\mathrm{Na}$ sequencia é apresentado o Quadro 1 com resumo dos construtos de pesquisa após aplicação da Analise Fatorial:

\begin{tabular}{|c|c|c|}
\hline Fator & Variável & Descrição \\
\hline \multirow{12}{*}{$\begin{array}{l}\text { Políticas de } \\
\text { Gestão de } \\
\text { Pessoas }\end{array}$} & CONT_CAR & Este banco contrata os funcionários visando uma carreira na empresa. \\
\hline & SAL_DES & Neste banco os salários são determinados pelo desempenho individual. \\
\hline & PROC_SEL & O processo de seleção nesse banco é rigoroso. \\
\hline & EQUIPE & No meu setor é enfatizado o trabalho em equipe. \\
\hline & DES_I_B & $\begin{array}{l}\text { Este banco possui um sistema de remuneração que recompensa tanto o } \\
\text { desempenho individual como o desempenho do banco. }\end{array}$ \\
\hline & VALORES & $\begin{array}{l}\text { Este banco possui um conjunto claro de valores compartilhados por todas } \\
\text { as pessoas. }\end{array}$ \\
\hline & DEC_PART & As decisões em meu setor são participativas. \\
\hline & AVAL_DES & $\begin{array}{l}\text { Neste banco, a avaliação de desempenho dos funcionários é realizada } \\
\text { para melhorar os resultados de cada um. }\end{array}$ \\
\hline & QUAL_FUNC & $\begin{array}{l}\text { O banco oferece oportunidades constantes de qualificação para os } \\
\text { funcionários. }\end{array}$ \\
\hline & CUMP_EXP & Eu sempre cumpro as expectativas do banco em que trabalho. \\
\hline & VAL_RES & O banco valoriza os resultados dos seus colaboradores. \\
\hline & FOCO_RES & $\begin{array}{l}\text { Foco absoluto nos resultados para os empregados, para a organização, } \\
\text { para os clientes e investidores. }\end{array}$ \\
\hline \multirow{4}{*}{$\begin{array}{l}\text { Liderança: } \\
\text { motivação e } \\
\text { eficiência na } \\
\text { obtenção de } \\
\text { resultados }\end{array}$} & FEED_RES & $\begin{array}{l}\text { Retorno (Feedback) de colegas sobre as maneiras de como melhorar } \\
\text { resultados. }\end{array}$ \\
\hline & MOT_RES & Líderes motivados com a obtenção de resultados positivos \\
\hline & RAP_RES & Rapidez na busca de resultados. \\
\hline & CAR_CULT & $\begin{array}{l}\text { Os líderes devem representar as características da cultura (valores) do } \\
\text { banco e setor. }\end{array}$ \\
\hline \multirow{5}{*}{$\begin{array}{l}\text { Liderança: } \\
\text { orientação } \\
\text { para resultados }\end{array}$} & INOV & Inovação em todas as áreas sob a sua influência. \\
\hline & LID_RES & Liderança no seu setor orientada para resultados. \\
\hline & USO_CAP & $\begin{array}{l}\text { Utilização total das capacidades dos funcionários nas oportunidades de } \\
\text { qualificação. }\end{array}$ \\
\hline & MED_RES & Mensuração dos padrões de resultados. \\
\hline & COMUM & $\begin{array}{l}\text { A comunicação interna no banco é considerada como um recurso } \\
\text { imprescindível para obter resultados. }\end{array}$ \\
\hline
\end{tabular}

\section{Quadro 1 - Resumo dos Construtos de Pesquisa}

O questionário foi aplicado no mês de Março, caracterizando-se como ocasional única. A população pesquisada envolveu funcionários operacionais, supervisores e gerentes das Instituições Financeiras, sem identificar o nome e porte das agências. A cidade possui 13 instituições financeiras, sendo composta por 2 bancos públicos (4 agencias) e 5 bancos privados (9 agencias). A amostra foi aleatória e por conveniência, contando com 124 respondentes, ou seja, $51,90 \%$ dos 239 bancários da cidade. 
Os pressupostos principais assegurados na análise fatorial foram: KMO, MSA, RMSR, Comunalidade e Variância Total explicada. O teste de KMO (Kaiser-Meyer-Olkin) confronta as correlações entre pares de indicadores com as correlações residuais. Para validar a AF é necessário que KMO seja maior que $0,5 \mathrm{com}$ a significância dada pelo teste de Bartlett $(\alpha<$ 0,05). O teste MSA (Measures Sample Adequacy) determina individualmente a adequação de cada uma das variáveis (indicadores) na amostra (FIELD, 009).

O RMSR (Root Mean Square Residual) é utilizado para calcular a qualidade do ajuste do modelo. Este índice resulta do quadrado médio entre as diferenças das variâncias-covariâncias estimadas pelo modelo e as variâncias-covariâncias observadas (SCHUMACKER; OMAX, 1996).

A Comunalidade é a quantidade de variância de um indicador explicada pelo(s) fator(es) extraído(s). Comunalidade menor que 0,5 significa que mais de $50 \%$ da variância do indicador (variável) não foi captada pelo(s) fator(es), devendo ser excluído do modelo. A Variância Total Explicada inclui a variância de todos os indicadores explicada pela variável latente. Recomendase um índice de pelo menos $60 \%$ ou dois terços (FIELD, 009).

A análise fatorial utilizada neste estudo é baseada na matriz de correlações e no método de análise de componentes principais. Para determinação do número de fatores representativos foram utilizados os autovalores superiores a 1. Optou-se pela preservação da ortogonalidade dos eixos, adotando-se o método de rotação varimax.

\section{$4 \quad$ Resultados e Discussões}

Neste tópico, são expostos e discutidos os resultados da pesquisa. Na primeira parte, apresenta-se a descrição dos professores respondentes e, em seguida, a análise dos dados e informações coletadas, realizados por meio da análise fatorial.

\subsection{Descrição da Amostra}

A maioria dos bancários respondentes são mulheres. Esse dado demostra a forte inserção das mulheres no mercado de trabalho e principalmente inseridas em um cenário que anos atrás era ocupada predominantemente por homens, como apontadas por Alves (2014). Os dados apresentados são semelhantes as estatísticas de participação feminina no sistema financeiro nacional, onde as mulheres representavam $48,7 \%$ do sistema como um todo, nos bancos públicos com 42,8\% dos empregados e, nos bancos privados com 53,4\% (DIEESE, 2013).

A maioria dos participantes são pessoas de até 30 anos de idade, o que é considerado uma faixa etária jovem, podendo ser essa uma tendência para o cenário financeiro da cidade. Em seguida vem a faixa etária de 31 a 35 anos e por último, pessoas entre 46 a 49 anos. Os dados do Dieese (2013) classifica a faixa etária dos 30 aos 39 anos em que se concentram a maioria dos bancários $(33,2 \%)$.

A parte mais significativa da amostra possui ensino superior completo, seguido de pósgraduação completo. Apenas uma pequena parte da amostra ainda não concluiu o ensino médio, o que caracteriza os colaboradores por apresentar bom grau de instrução. Os dados fornecidos pelo Dieese (2013) demonstram que os bancários da cidade pesquisada seguem a mesma tendência nacional apresentando ensino superior completo.

A maioria dos respondentes estão no cargo de gerencia, seguido dos agentes e caixas. A pesquisa também contou, com menor participação, de estagiários, supervisores, tesoureiros e assistentes jurídicos que não haviam sido classificados por cargo. 


\begin{tabular}{|c|c|c|c|c|c|}
\hline \multirow{2}{*}{ Gênero } & \multicolumn{4}{|c|}{ Cargo/Função } & \multirow[b]{2}{*}{ Total } \\
\hline & Gerente & Agente & Caixa & Outro & \\
\hline Masculino & 16 & 13 & 17 & 12 & 58 \\
\hline Feminino & 26 & 21 & 10 & 9 & 66 \\
\hline Total & 42 & 34 & 27 & 21 & 124 \\
\hline
\end{tabular}

Tabela 1 - Perfil de Gênero e Cargo/Função

A Tabela 1 reafirma as estatísticas já apontadas anteriormente, pois a posição de gerência é ocupada primeiramente por mulheres, que também assumem maior proporção no cargo de agente bancário. Pesquisas da Dieese (2013) apontam que os cargos de "Gerentes" são ocupados por $52,5 \%$ de mulheres, o que deixa o município como seguidor da tendência nacional.

\begin{tabular}{lccccc}
\hline \multirow{2}{*}{\multicolumn{1}{c}{ Escolaridade }} & \multicolumn{3}{c}{ Cargo/Função } & \multirow{2}{*}{ Total } \\
\cline { 2 - 5 } & Gerente & Agente & Caixa & Outro & \\
\hline Ensino Médio ou menos & - & 3 & 2 & 4 & 9 \\
Superior Incompleto & 3 & 6 & 3 & 6 & 18 \\
Superior Completo & 16 & 13 & 11 & 6 & 46 \\
Pós-Graduação Incompleto & 6 & 4 & 6 & 1 & 17 \\
Pós-Graduação Completo & 17 & 8 & 5 & 4 & 34 \\
Total & $\mathbf{4 2}$ & $\mathbf{3 4}$ & $\mathbf{2 7}$ & $\mathbf{2 1}$ & $\mathbf{1 2 4}$ \\
\hline
\end{tabular}

Tabela 2 - Perfil de Escolaridade e Cargo/Função

Conforme a Tabela 2, os cargos mais altos pesquisados, que são os gerentes, possuem pósgraduação completo seguidos de superior completo. Esses dados permitem a conclusão de que quanto mais elevada a posição dentro da organização, maior a preocupação com o grau de instrução, preparo que facilita uma gestão eficiente e eficaz dentro das instituições.

A média geral de tempo de empresa encontrado foi de 9,9 anos, ou seja, uma média elevada se comparado a outros setores como o construção civil onde $50 \%$ dos trabalhadores apresentam até 3 meses de empresa (EXCELENCIAEMGESTAO, 2014).

A maioria dos participantes da pesquisa avaliou as questões relativas às politicas de gestão de pessoas para o seu banco como "importante" e de "total importância". Isso demonstra a satisfação dos colaboradores com as políticas empregadas.

Segundo critérios apresentados por Albuquerque (2002) a estratégia identificada é a de comprometimento. De maneira geral as instituições financeiras da cidade valorizam o trabalho em equipe, permitindo as decisões sejam tomadas de forma participativa. Oferecem um plano de encarreiramento, onde, por meritocracia e resultados alcançados, os funcionários podem crescer e se desenvolver. Buscam valorizar seus talentos através de constantes qualificações e elogios, além da criação de condições favoráveis à motivação individual.

Em relação as Políticas de Gestão de Pessoas, as médias gerais ficaram entre 4,15\% e 4,40\%, estes dados afirmam a boa aceitação por parte dos funcionários com as políticas de gestão de pessoas adotados, que neste caso é a política de comprometimento.

Já em relação as características dos líderes, a frequência das características dos líderes no seu setor e no banco, a maioria dos participantes atribuiu à classificação "importante" e de "total importância" pela postura adotada pelos líderes dentro das instituições.

De acordo com critérios estabelecidos por Ulrich (2000) a liderança percebida nos bancos é a orientada para resultados. O foco dos funcionários se concentra nos resultados e metas da organização, demonstrando grande comprometimento. A equipe busca acompanhar os resultados, melhoria contínua e a rapidez nos resultados. Para que tudo isso ocorra, os líderes atuam ativamente fornecendo inspiração, motivação e direção clara para sua equipe.

\subsection{Análise Fatorial}

Como o número de variáveis utilizadas é elevado (27), e há elevada multicolinearidade entre as variáveis, procedeu-se a Análise Fatorial baseada na matriz de correlações e no método dos 
componentes principais com rotação varimax, onde o número de fatores extraídos corresponderam aos autovalores superiores a 1.

Para explicação da Tabela 3 e 4 a seguir, procederam-se as análises dos seguintes aspectos, para validação e retenção de cada uma das variáveis:

a) $\quad \mathrm{MSA}>0,6$;

b) Variância individual explicada superior à $60 \%$;

c) Carga fatorial, da matriz rotacionada, superior a $60 \%$;

d) Carga fatorial concentrada em um único fator;

Tendo por base os critérios de validação definidos, foram excluídas da análise as seguintes variáveis:

a) REC_SOC: Variância individual explicada menor que 60\%;

b) COM_MET e MEL_RES: Cargas fatoriais concentradas em mais de um fator;

c) OP_ES e PROD_RES: Cargas fatoriais menores que $60 \%$.

Com as demais variáveis pode-se validar o modelo com MSA $>0,9$ para todas as variáveis retidas. Pelo Teste de Kaiser-Keyer-Olkin $(\mathrm{KMO}=0,932)$ e de Esfericidade de Bartlett $(\mathrm{p}<$ 0,001), o modelo de AF empregado mostrou-se altamente significativo.

\begin{tabular}{|c|c|c|c|c|c|c|c|c|c|}
\hline \multirow[t]{2}{*}{ Var. } & \multicolumn{3}{|c|}{ Valores próprios iniciais } & \multicolumn{3}{|c|}{$\begin{array}{c}\text { Somas de extração de } \\
\text { carregamentos ao quadrado }\end{array}$} & \multicolumn{3}{|c|}{$\begin{array}{c}\text { Somas rotativas de carregamentos } \\
\text { ao quadrado }\end{array}$} \\
\hline & Total & $\%$ var. & $\%$ cum. & Total & $\%$ var. & $\%$ cum. & Total & $\%$ var. & $\%$ cum. \\
\hline 1 & 13,924 & 66,307 & 66,307 & 13,924 & 66,307 & 66,307 & 7,684 & 36,591 & 36,591 \\
\hline 2 & 1,435 & 6,834 & 73,141 & 1,435 & 6,834 & 73,141 & 4,468 & 21,276 & 57,867 \\
\hline 3 & 1,045 & 4,975 & 78,115 & 1,045 & 4,975 & 78,115 & 4,252 & 20,249 & 78,115 \\
\hline 4 & 0,677 & 3,222 & 81,337 & & & & & & \\
\hline 5 & 0,551 & 2,625 & 83,962 & & & & & & \\
\hline 6 & 0,499 & 2,378 & 86,339 & & & & & & \\
\hline 7 & 0,466 & 2,217 & 88,556 & & & & & & \\
\hline 8 & 0,414 & 1,973 & 90,530 & & & & & & \\
\hline 9 & 0,312 & 1,487 & 92,017 & & & & & & \\
\hline 10 & 0,276 & 1,316 & 93,333 & & & & & & \\
\hline 11 & 0,232 & 1,104 & 94,437 & & & & & & \\
\hline 12 & 0,216 & 1,029 & 95,466 & & & & & & \\
\hline 13 & 0,183 & 0,871 & 96,337 & & & & & & \\
\hline 14 & 0,158 & 0,751 & 97,087 & & & & & & \\
\hline 15 & 0,150 & 0,716 & 97,803 & & & & & & \\
\hline 16 & 0,123 & 0,584 & 98,387 & & & & & & \\
\hline 17 & 0,100 & 0,477 & 98,864 & & & & & & \\
\hline 18 & 0,085 & 0,406 & 99,270 & & & & & & \\
\hline 19 & 0,058 & 0,276 & 99,546 & & & & & & \\
\hline 20 & 0,053 & 0,254 & 99,800 & & & & & & \\
\hline 21 & 0,042 & 0,200 & 100,000 & & & & & & \\
\hline
\end{tabular}

Tabela 3 - Variância Total Explicada

Na Tabela 3 constata-se a retenção de três fatores que, em conjunto, explicam $78,1 \%$ das variâncias das 21 variáveis envolvidas na análise, de forma que os fatores obtidos são substitutos adequados do conjunto das variáveis.

$\mathrm{Na}$ matriz rotacionada (Tabela 4) convergida em 5 repetições, observaram-se os agrupamentos das variáveis em seus respectivos fatores.

\begin{tabular}{|c|c|c|c|}
\hline \multirow{2}{*}{ Variáveis } & \multicolumn{3}{|c|}{ Componente } \\
\hline & Fator 1 & Fator 2 & Fator 3 \\
\hline CONT_CAR & 0,835 & & \\
\hline SAL_DES & 0,826 & & \\
\hline PROC_SEL & 0,788 & & \\
\hline DES_I_B & 0,772 & & \\
\hline EQUIPE & 0,764 & & \\
\hline
\end{tabular}




\begin{tabular}{llll} 
VALORES & 0,748 & & \\
DEC_PART & 0,717 & & \\
QUAL_FUNC & 0,674 & & \\
AVAL_DES & 0,665 & & \\
CUMP_EXP & 0,654 & & \\
VAL_RES & 0,639 & & \\
FOCO_RES & 0,635 & & \\
FEED_RES & & 0,873 & \\
MOT_RES & & 0,859 & \\
RAP_RES & & 0,790 & \\
CARAC_CULT & & 0,739 & \\
LID_RES & & & 0,798 \\
COMUN & & & 0,702 \\
INOV & & & 0,697 \\
USO_CAP & & 0,656 \\
\hline
\end{tabular}

Tabela 4 - Matriz Rotacionada

Com base na matriz rotacionada (Tabela 4) foi construído cada um dos construtos, conforme descritos nos Quadros 1, 2 e 3.

\begin{tabular}{|c|l|l|}
\hline Fat & \multicolumn{1}{|c|}{ Variável } & \multicolumn{1}{c|}{ Descrição } \\
\hline \multirow{4}{*}{} & CONT_CAR & Este banco contrata os funcionários visando uma carreira na empresa. \\
\cline { 2 - 3 } & SAL_DES & Neste banco os salários são determinados pelo desempenho individual. \\
\cline { 2 - 4 } & PROC_SEL & O processo de seleção nesse banco é rigoroso. \\
\cline { 2 - 4 } & EQUIPE & No meu setor é enfatizado o trabalho em equipe. \\
\cline { 2 - 4 } & \multirow{4}{*}{$\mathbf{1}$} & $\begin{array}{l}\text { Este banco possui um sistema de remuneração que recompensa tanto o desempenho } \\
\text { individual como o desempenho do banco. }\end{array}$ \\
\cline { 2 - 4 } & VALORES & Este banco possui um conjunto claro de valores compartilhados por todas as pessoas. \\
\cline { 2 - 4 } & DEC_PART & As decisões em meu setor são participativas. \\
\cline { 2 - 4 } & AVAL_DES & $\begin{array}{l}\text { Neste banco, a avaliação de desempenho dos funcionários é realizada para melhorar } \\
\text { os resultados de cada um. }\end{array}$ \\
\cline { 2 - 4 } & QUAL_FUNC & O banco oferece oportunidades constantes de qualificação para os funcionários. \\
\cline { 2 - 4 } & CUMP_EXP & Eu sempre cumpro as expectativas do banco em que trabalho. \\
\cline { 2 - 4 } & VAL_RES & O banco valoriza os resultados dos seus colaboradores. \\
\cline { 2 - 4 } & FOCO_RES & $\begin{array}{l}\text { Foco absoluto nos resultados para os empregados, para a organização, para os } \\
\text { clientes e investidores. }\end{array}$ \\
\hline
\end{tabular}

\section{Quadro 2 - Construto 1 - Políticas de Gestão de Pessoas}

Em relação ao Quadro 2, no primeiro construto retirou-se 12 variáveis, das quais 11 originalmente figuravam no conjunto de questões que procuraram medir os aspectos de Políticas de Gestão de Pessoas. Apenas uma variável, FOCO_RES, que figurava na conjunto de questões de Características dos Líderes, foi retida nesse construto. Possivelmente "Foco em Resultados", para o caso da presente amostra, seja um aspecto mais aderente à "Políticas de Gestão de Pessoas" do que a "Características dos Líderes".

\begin{tabular}{|c|l|l|}
\hline Fat & \multicolumn{1}{|c|}{ Variável } & \multicolumn{1}{c|}{ Descrição } \\
\hline \multirow{4}{*}{2} & FEED_RES & Retorno (Feedback) de colegas sobre as maneiras de como melhorar resultados. \\
\cline { 2 - 3 } 2 & MOT_RES & Líderes motivados com a obtenção de resultados positivos \\
\cline { 2 - 3 } & RAP_RES & Rapidez na busca de resultados. \\
\cline { 2 - 3 } & CAR_CULT & Os líderes devem representar as características da cultura (valores) do banco e setor. \\
\hline
\end{tabular}

Quadro 3 - Construto 2 - Liderança: motivação e eficiência na obtenção de resultados

Percebe-se, Quadro 3, que no segundo construto foram retidas 4 variáveis, das quais todas figuram o conjunto original de questões que procuraram medir a liderança em conjunto com a motivação e eficiência na obtenção de resultados. 


\begin{tabular}{|c|l|l|}
\hline Fat & Variável & \multicolumn{1}{c|}{ Descrição } \\
\hline \multirow{4}{*}{3} & INOV & Inovação em todas as áreas sob a sua influência. \\
\cline { 2 - 3 } & LID_RES & Liderança no seu setor orientada para resultados. \\
\cline { 2 - 3 } & USO_CAP & Utilização total das capacidades dos funcionários nas oportunidades de qualificação. \\
\cline { 2 - 3 } & MED_RES & Mensuração dos padrões de resultados. \\
\cline { 2 - 3 } & COMUM & $\begin{array}{l}\text { A comunicação interna no banco é considerada como um recurso imprescindível para } \\
\text { obter resultados. }\end{array}$ \\
\hline
\end{tabular}

Quadro 4 - Construto 2 - Liderança: orientação para resultados

Observa-se, Quadro 4, que no terceiro construto foram retidas 5 variáveis, das quais todas figuram o conjunto original de questões que procuraram medir a liderança orientada para resultados.

\begin{tabular}{|c|c|c|c|c|c|c|}
\hline Fatores & $\begin{array}{l}\text { Variáveis } \\
\text { Retidas }\end{array}$ & MAS & Comun. & $\begin{array}{l}\text { Alpha de } \\
\text { Cronbach }\end{array}$ & $\begin{array}{c}\text { Carga } \\
\text { Fatorial }\end{array}$ & $\begin{array}{l}\text { Variância } \\
\text { Explicada }\end{array}$ \\
\hline \multirow{12}{*}{$\begin{array}{l}\text { Políticas de } \\
\text { Gestão de } \\
\text { Pessoas }\end{array}$} & CONT_CAR & 0,914 & 0,819 & \multirow{12}{*}{0,964} & 0,835 & \multirow{12}{*}{$36,8 \%$} \\
\hline & SAL_DES & 0,947 & 0,875 & & 0,826 & \\
\hline & PROC̄_SEL & 0,940 & 0,849 & & 0,788 & \\
\hline & EQUIPE & 0,929 & 0,654 & & 0,764 & \\
\hline & DES_I_B & 0,944 & 0,754 & & 0,772 & \\
\hline & VALORES & 0,968 & 0,806 & & 0,748 & \\
\hline & DEC_PART & 0,960 & 0,610 & & 0,717 & \\
\hline & AVAL__DES & 0,959 & 0,737 & & 0,665 & \\
\hline & QUAL_FUNC & 0,929 & 0,693 & & 0,674 & \\
\hline & CUMP_EXP & 0,955 & 0,633 & & 0,654 & \\
\hline & VAL_RES & 0,964 & 0,752 & & 0,639 & \\
\hline & FOCO_RES & 0,929 & 0,649 & & 0,635 & \\
\hline \multirow{4}{*}{$\begin{array}{c}\text { Liderança: } \\
\text { Motivação e } \\
\text { Eficiência em } \\
\text { Resultados }\end{array}$} & FEED_RES & 0,880 & 0,849 & \multirow{4}{*}{0,947} & 0,873 & \multirow{4}{*}{$22,4 \%$} \\
\hline & MOT_RES & 0,886 & 0,916 & & 0,859 & \\
\hline & RAP_RES & 0,923 & 0,854 & & 0,790 & \\
\hline & CAR_CULT & 0,920 & 0,838 & & 0,739 & \\
\hline \multirow{4}{*}{$\begin{array}{l}\text { Liderança: } \\
\text { Orientação para } \\
\text { Resultados }\end{array}$} & LID_RES & 0,900 & 0,766 & \multirow{4}{*}{0,859} & 0,798 & \multirow{4}{*}{$17,0 \%$} \\
\hline & COMUM & 0,913 & 0,616 & & 0,702 & \\
\hline & INOV & 0,858 & 0,767 & & 0,697 & \\
\hline & USO_CAP & 0,875 & 0,788 & & 0,656 & \\
\hline
\end{tabular}

Tabela 5 - Resumo da Análise Fatorial

Quanto aos valores do Alfa de Cronbach, que indicam a consistência interna, ou confiabilidade, da escala, para Malhotra (2006), o valor esperado de confiabilidade é no mínimo 0,6 , sendo que valores inferiores podem indicar uma consistência interna insatisfatória. No resumo da análise fatorial, Tabela 5, o Alpha de Cronbach encontrado no constructo 1 foi de 0,964, seguido de 0,947 (constructo 2) e 0,859 (constructo 3), sendo considerado com consistencia interna adequada. Já o MSA, que segundo Field (2009), determina individualmente a adequação de cada uma das variáveis na amostra, apresentou seus valores todos entre 0,858 e 0,968, demonstrando elevada adequação ao modelo, já que a base adotada é MSA > 0,6. A seguir apresenta-se as considerações finais do artigo.

\section{Considerações Finais}

Este estudo teve como ponto principal analisar os estilos de liderança, a orientação para resultados, e as praticas de gestão estratégica de pessoas utilizadas pelas instituições financeiras (públicas e privadas). Para tanto, foi realizado um estudo de caso com abordagem quantitativa, caracterizado como exploratório e descritivo em 13 agencias bancárias.

Como perfil geral dos bancários respondentes encontrou-se predominância do sexo feminino, com até 30 anos de idade, o que é considerado uma faixa etária jovem. A parte mais significativa da amostra possui ensino superior completo, seguido de pós-graduação completo. A maioria 
estão no cargo de gerencia, seguido dos agentes e caixas, com média geral de tempo de empresa de 9,9 anos.

Identificou-se uma tendência nos gestores para a liderança transformada, o que segundo Limongi-França e Arellano (2002) é visto como positivo, pois esses líderes apresentam características capazes de influenciar a mudança de atitudes e comportamentos dos funcionários, além de criar um comprometimento com a missão e objetivos da organização, motivando os seguidores a fazerem esforços extraordinários pela empresa. A media de aceitação dos colaboradores com relação às características de seus líderes ficaram 4,95\% e 4,35\%, resultados esses classificados na pesquisa como "Importante" e "Total Importância".

A liderança elencada pelos respondentes é a orientada para resultados, que segundo Ulrich (2000) é a mais adequada, pois para se atingir a eficiência e a eficácia organizacional, as empresas devem ter objetivos e metas que possibilitem a consecução de algo. O produto da liderança eficaz converte aspirações em ações. Essas aspirações surgem de estratégias, metas, missões, visões, previsões e planos. As organizações constroem uma marca de liderança orientada para os resultados de acordo com quatro passos a seguir: 1) Acreditar na importância da liderança; 2) Desenvolver uma marca de liderança; 3) Avaliar os líderes e encontrar os pontos fracos; e 4) Investir em liderança.

A maioria dos participantes avaliou as questões relativas às politicas de gestão de pessoas para o seu banco como "importante" e de "total importância", demonstrando a satisfação dos colaboradores com as políticas empregadas, com médias gerais nas pesquisas entre $4,15 \%$ e $4,40 \%$, esse resultado classifica o foco das instituições financeiras no comprometimento. Isso se da através da análise das agencias bancárias, comparadas com o quadro das características em relação às estratégias de controle e comprometimento expostos por Albuquerque (2002).

As principais contribuições deste trabalho são para o entendimento do tema estudado e para a identificação das lideranças e gestão estratégica de pessoas nas instituições financeiras da cidade. Para as organizações de maneira geral é relevante, pois os dados da pesquisa demonstram que quanto maior for o investimento em políticas de gestão estratégica de pessoas com visão transformada, e orientada para resultados, maior a satisfação dos colaboradores.

Por fim, as limitações do estudo se referem ao fato de ser realizado apenas com os bancários de uma determinada cidade, o que não permite a generalização das conclusões para instituições financeiras de outros municípios. Para estudos futuros, sugere-se a aplicação da pesquisa tanto para instituições financeiras de outras cidades, como em outros setores a exemplo de indústria, comércio e serviços, entre outras.

\section{Referências}

ALBUQUERQUE, L. G. A gestão estratégica de pessoas. In: FLEURY, M. T. L (Org.). As pessoas na organização. São Paulo: Editora Gente, 2002.

ALBUQUERQUE, L. G. Estratégias de recursos humanos e competitividade. In: VIEIRA, M. M. F.; OLIVEIRA, L. M. B. (orgs.). Administração contemporânea: perspectivas estratégicas. São Paulo: Atlas, 1999.

ALVES, J. E. D. As taxas de atividade de homens e mulheres no mercado de trabalho no brasil. Disponível em: https://demografiaunicamp.wordpress.com/2014/01/04/as-taxas-deatividade-de-homens-e-mulheres-no-mercado-de-trabalho-no-brasil-artigo-de-jose-eustaquiodiniz-alves/ . Acesso em 25 de março de 2016.

ANDRADE, S. M.; LOPES. E.; STEFANO, S. F. Do Controle ao Comprometimento: Uma Análise da Gestão Estratégica de Pessoas em Empresas Prestadoras de Serviços de Grande Porte, no Interior do Paraná. REUNA, Belo Horizonte - MG, Brasil, v.18, n.3, p.91-110, Jul. - Set.. 2013 - ISSN 2179-8834.

ARMSTRONG, M. Strategic Human Resource Management: A Guide to Action. Philadelphia: Kogan Page, 2008. 
AROMA, W.; DA SILVA, A. C. A Influência dos Líderes na Melhoria dos Serviços de Atendimento em Agências Bancárias Atuando no Processo de Aprendizagem dos Atendentes. In: Anais... ENANPAD, 2003, Atibaia, 2003. s.n.

BANCARIOSRIO. Discriminação das mulheres nos bancos aumenta com ascensão e escolarização. Disponível em: http://www.bancariosrio.org.br/2013/opiniao/item/26149discriminacao-das-mulheres-nos-bancos-aumenta-com-ascensao-e-escolarizacao. Acesso em 08 de maio de 2014.

BERNARDIN, M. L.; STEFANO, S. R.; ZAMPIER, M. A Gestão de Talentos. Editora Unicentro, 2011.

BOWDITCH, J. L.; BUONO, A. F. Elementos do comportamento organizacional. São Paulo: Pioneira Thomson, 2002.

COOPER, D. R.; SCHINDLER, P. S. Business Reserch Methods. Irwin: McGraw-Hill, 2003.

CRESWELL, J. W. Projeto de pesquisa: métodos qualitativo, quantitativo e misto. 2. ed. Porto Alegre: Artmed, 2007.

DIEESE. Desigualdade de gênero nos bancos. Disponível em:

http://www.contrafcut.org.br/download/Arquivo/13124161922.pdf. Acesso em 08 de maio de 2014.

DIJK, R. V.; EIGENHUIS, A. P. HR Strategy for the High Performing Business. Philadelphia: Kogan Page, 2008.

DRUCKER, P. F. Administrando em Tempos de Grandes Mudanças. São Paulo: Pioneira, 1999.

DUTRA, J. S. Competências: conceitos e instrumentos para a gestão de pessoas na empresa moderna. São Paulo: Atlas, 2013.

EXCELEnCIAEMGESTAO. Perfil dos Operários da Construção civil. Disponível em: http://www.excelenciaemgestao.org/Portals/2/documents/cneg4/anais/T7_0049_0404.pdf.

Acesso em 08 de maio de 2014.

FEBRABAN. A Febraban. Disponível em: http://www.febraban.org.br/Febraban.asp/. Acesso em 30 de setembro de 2013.

FIELD, A. Descobrindo a estatística usando o SPSS. Porto Alegre: Artmed, 2009.

FISHER, A.L. Um resgate conceitual e histórico dos modelos de gestão de pessoas. In: FLEURY, M.T. et al., As Pessoas na Organização. São Paulo: Ed. Gente. 2002.

FOLEY, Jeff; SMITH, Perry. Rules \& Tools for Leaders. USA: Penguin, 2010.

FRAGOSO, Samarina de Araújo. Gestão estratégica de pessoas como fonte de vantagens competitivas nas organizações. REBRAE. Revista Brasileira de Estratégia, Curitiba, v. 2, n. 3, p. 307-315, set./dez. 2009.

LIMONGI-FRANÇA, A. C.; ARELLANO, E. B. Liderança, poder e comportamento organizacional. In: FLEURY, M. T. L (Org.). São Paulo: Editora Gente, 2002. p. 259-269.

MALHOTRA, N. K. Pesquisa de Marketing: Uma orientação aplicada. $4^{\mathrm{a}}$ ed. Trad. Laula Bocco. Porte Alegre: Bookman, 2006.

MASCARENHAS, A. O. Gestão estratégica de pessoas: evolução, teoria e crítica. São Paulo: Cengage Learning, 2008.

MAXIMIANO, A. C. A. Administração de projetos. 2. ed. São Paulo: Atlas, 2009.

MONTANA, J. P.; CHARNOV, H. B. Administração. São Paulo: Saraiva, 2003.

RAIFUR, Léo. Fatores determinantes do desempenho de pequenas e médias empresas da região centro-sul do estado do Paraná. Tese (doutorado) Universidade de São Paulo, 2013.

ROBBINS, S. P. Administração. São Paulo: Saraiva, 2011.

SCHUMACKER, R. E.; LOMAX, R. G. A Beginner's Guide to Structural Equation Modeling. Lawrence Erlbaum Associates. Mahwah, New Jersey, 1996. 
STEFANO, Silvio Roberto. Liderança e suas relações com a estratégia de gestão de pessoas e o bem-estar organizacional: um estudo comparativo em duas instituições financeiras internacionais. Tese (doutorado) Universidade de São Paulo, 2008.

ULRICH, D.; ZENGER, J.; SMALLWOOD, N. Liderança orientada para resultados. São Paulo: Campus, 2000. 